\title{
Evaluation of two types of bleaching gel and light source on whitening of teeth
}

\author{
Baharan Ranjbar Omidi ${ }^{1}$, Mohammad Nouri ${ }^{2}$ and Negin Farahmandpour*3 \\ ${ }^{1}$ Assistant Professor, Dental Caries Prevention Research Center, Qazvin University of Medical Sciences, \\ Qazvin, Iran \\ ${ }^{2}$ Dentist, Tehran Iran \\ ${ }^{3}$ Restorative Dentistry Specialist, Kermanshah, Iran
}

\begin{abstract}
Today, increasing desire for tooth brightening, make bleaching gel and light sources as a popular method for tooth whitening. The aim of this study was effect of combination of bleaching gel and light source on the teeth whitening. In this study 60 healthy human anterior teeth were randomly dividedin three groups $(n=20)$. The first groupwas withoutlight, the second one LED andon the third group QTH light was used. Each group was divided into two subgroups whichhad two types of hydrogen peroxide bleaching gelsincluding 37.5\% Pola office and 40\% Opalescence Boost which were applied to them. The primary colors of teeth were measured, and then kept intea (200ml) for 7 days. After that each tooth color was measured for the second time. The teeth were bleached according to the protocol of each group: Immediately, after 3, 7 and 30 days they were measured by spectrophotometer. Data were analyzed by statistical software SPSS 20 and One-way ANOVA and Tukey testin alpha 0.05. Bleaching effectiveness of QTH significantly was increasedin both of bleaching gels as compared to LED and without using of light, at different times: instantly, 3 days and 7 days after bleaching, a month after bleaching, significant differences between the different methods was not seen. The results of this study showed thatin-office bleaching, with or without light is an effective method of beaching. QTH Light in the short term (one week) showed significant impact on teethwhitening in both bleach gel. However, within a month therewere no significant differences in all groups.
\end{abstract}

KEY WORDS: IN-OFFICE BLEACHING, HYDROGEN PEROXIDE, ACTIVATION LIGHT

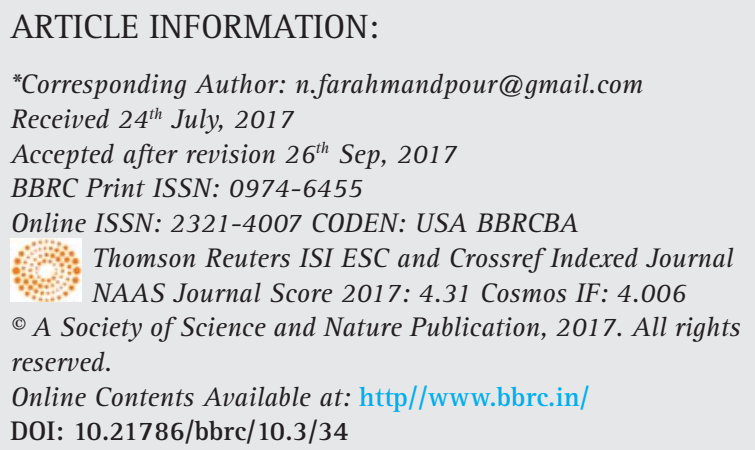




\section{INTRODUCTION}

In recent years, cosmetic dentistry has become an important part of restorative dentistry. In all ages, the teethappearances for patients are one of important aspects which influences on satisfaction of them.Desire of having a whiter tooth has increased due to attention of people to this novel that brighter teeth are healthier and morestylish (Barghi, 1998). The bleaching is very effective on teeth with high Hue and yellow tint (Ishikawa-Nagai, Terui, Ishibashi, Weber, \&t Ferguson, 2004). In fact, dental bleaching materials are oxidizing materials which difference in various techniques still stay controversial (Izquierdo-Barba, Torres-Rodríguez, Matesanz, \&t Vallet-Regí, 2015).

Today, several bleaching methods are used including: in-office professional, in-home professional (dentist supervised take-home) and products without a prescription (over-the-counter) (Caneppele, 2013). To speed up the bleaching process, increasing the concentration of chemicals or use different light devices recommended, (Sulieman, Addy, MacDonald, \&t Rees, 2004), (Buchalla Et Attin, 2007). Some advantages of in-office techniques like prevention of swallowing and contacting with oral soft tissue, reducing treatment time and controlling of the healing process make it as a suitable technique for most patients compared to other techniques (Luk, Tam, Et Hubert, 2004), (Tay, Kose, Loguercio, Et Reis, 2009).

Two important factors in estimating the teeth whitening product performance are peroxide concentration and the duration of its application. Studies have shown that higher concentrations of peroxide is required a smaller amount of gel (Sulieman et al., 2004). In today's inoffice bleaching carbamide peroxide and hydrogen peroxide are used mainly by heat or light-activated devices to accelerate the process of bleaching teeth (Sulieman et al., 2004), (Zhang et al., 2007). Most studies have suggested that light cure accelerated the degradation of peroxide (by increasing temperature) which led to theformations of higher free radicals(Sulieman et al., 2004), (Joiner, 2004), (Lima et al., 2009). today various light cure devices like Light-emitting diode(LED), halogen lamp, plasma arc lamp(PAC) are available, however, application of heat, light or laser devices should not be more than $5.5^{\circ} \mathrm{C}$ temperature due to preventing pulp chamber damage(Buchalla \&t Attin, 2007). Although, in recent years the use of laser bleaching is generally available as an energy source but LED require nearly low cost, and less energy (Kurachi, Tuboy, Magalhães, \&t Bagnato, 2001). There is controversy about the effectiveness of different light on teeth bleaching. although some researchers have reported benefits,however others showed no effects on bleaching, (Ishikawa-Nagai et al., 2004, Lima et al., 2009, Polydorou, Wirsching, Wokewitz, \&t Hahn, 2013).
Polydorou et al. (2013) have reported that QTH is more effective than laser bleaching, while Hahn et al. (2013) did not investigate any improvement with LED and laser in bleaching teeth. In another study which evaluated six different light resulted that the diode laser, QTH and LED had a significant impact on Teeth Whitening (Domínguez et al., 2011) Similarly, Kossatz et al., compared effect of LED and laser on 35\% hydrogen peroxide bleaching gel and reported no significant differences (Kossatz et al., 2011).

In another study where 35\% hydrogen peroxide was used, LED, QTH, plasma arc lamp, argon laser was used and they have been reported no effect on tooth bleaching (Lima et al., 2009). Clinician should be aware of any risks regarding to bleaching process (Alqahtani, 2014). The aim of this study was to evaluate effect of LED and QTH light on teeth whitening, since using of any type of light as an additional device is questionable in-office bleaching.

\section{MATERIAL AND METHODS}

In vitro experimental study, the 60 human anterior teeth were selected. First teeth were checked for any defects, cracks, decays or fillings. Then selected teeth after scaling, brushing (for 10 seconds with pumice and water by prophylaxis rubber cup then cleaned with ultrasonic cleaner, and stored for one week in the solution $0.1 \%$ Thymol at $4^{\circ} \mathrm{C}$. While the entire of laboratory work used gloves, surgical masks and face shields (Kohn et al., 2003), (Kumar, Sequeira, Peter, \&t Bhat, 2005), (Lolayekar, Bhat, \& $\mathrm{Bhat}$, 2007). The teeth were fixed in acrylic resin into the mold which the angle of light cure is perpendicular to the labial surface of the teeth. By creating four small holes (depth of about $0.5 \mathrm{~mm}$ ) with bur (No\#1) created squareshaped area (with dimensions of approximately $3 \mathrm{~mm}$ ) in the middle third of the labial teeth (Figure 1).

Labial surface of teeth were cleansed and brushed. Then all the teeth stored in Ringer (Ringer's Infusion, Shahid Ghazi Pharmaceutical Co., Tabriz-Iran). The teeth are completely dry with gauze and randomly divided into three groups $(20=n)$ with different bleaching protocols:The first group without light, the second LED light cure system (Woodpecker Dental LED.D Curing Light, China), the third group QTH light cure system (Coltolux 75 Curing Light-Coltene/Whaledent, USA). Each group divided into two subgroups of 10 teeth the first subgroup, hydrogen peroxide 37.5\% Polaoffice + (SDI, Australia) and in the second subgroup of hydrogen peroxide 40\% Opalescence Boost (Ultradent Products Inc, South ordan, UT USA) was used (figure 1).

The samples were placed on holder plate, white paper Leneta. Light source positioned at an angle of 45 degrees 


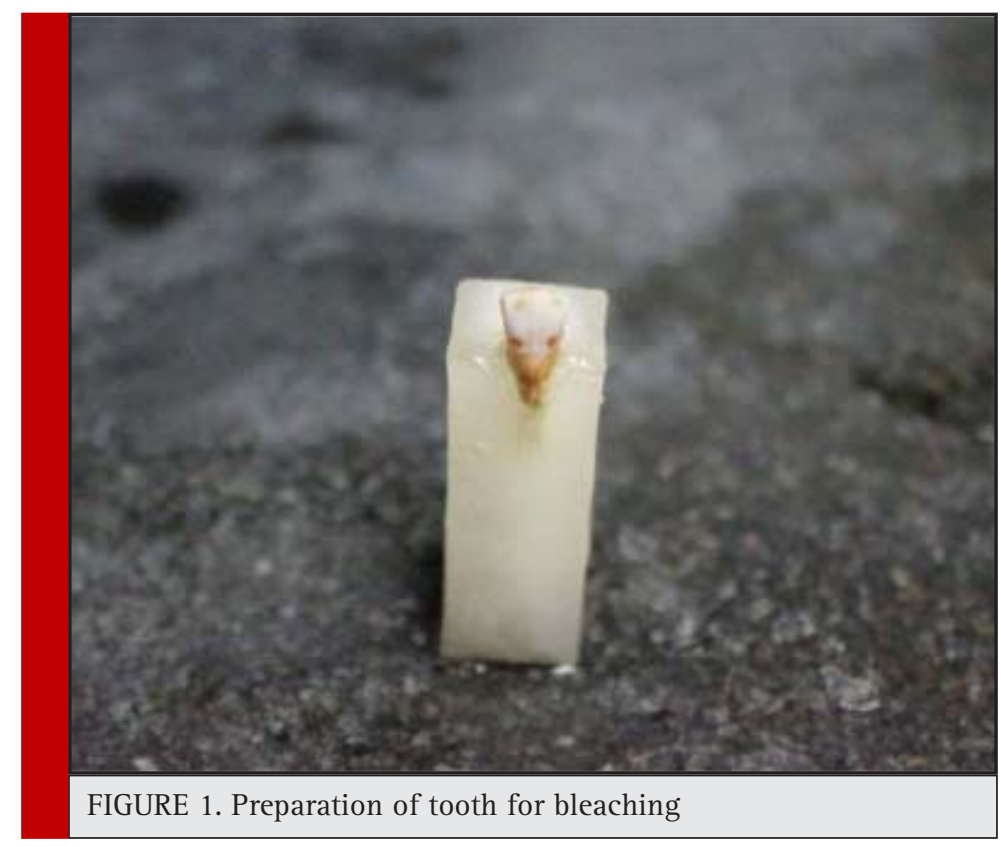

to a line perpendicular to the surface and spectrophotometer device (KONIKA MINOLTA CS2000, Japan) with an approximate angle of zero degrees relative to a line perpendicular to the sample surface and they were placed approximately $70 \mathrm{~cm}$.

The device was set at 0.2 degrees. This angle makes circular area with $2.4 \mathrm{~mm}$ in diameter in specimens. Three measurements were taken for each sample and average measurements were reported. Measurements were conducted under laboratory conditions at approximately $25^{\circ} \mathrm{C}$. The primary color of the teeth (M1) was measured by spectroradiometer. for changing the color, teeth were retained for 7 days in a mixture of tea (tea bags Golestan) obtained by the method Sulieman et al (Sulieman, Addy, \&t Rees, 2003). Teethwere brushed to remove pigments.

Then the teeth color was measured for the second time (M2). The teeth were bleached in all 3 groups according to the protocol set for each group, while the distance to the labial surface of the teeth were $5 \mathrm{~mm}$ to light tip. The intensity of light rays was measured before the start of each bleaching cycle using Radiometer (QTH $=370 \mathrm{mw} / \mathrm{cm} 2$, LED $=380 \mathrm{mw} / \mathrm{cm} 2$ ) to ensure constant light output is achieved at all stages of bleaching. In all three groups, the use of bleaching gel and light were performed exactly according to the manufacturer's instructions. A thin layer of (1 mm) Polaoffice bleaching gel was placed on the labial surface of the teeth for 8 minutes, then using clean cotton it was cleansed by gel then was stained with fresh gel.

This process was repeated three times (according to the manufacturer's instructions) and at the end all clear gel, rinsed with water and dried and the bleaching gel
Opalescence Boost, a thin layer ( $\mathrm{mm} 1)$ of gel on the labial surface of teeth put for 20 minutes (according to the manufacturer's instructions) and at the end all clear gel, rinsed with water and dried. Light application in groups 2 and 3 were three 8-minute for Polaoffice and a 20-minute period to Opalescence Boost.

Tooth color was measured immediately after bleaching (M3). Samples were put on Ringer with $37^{\circ} \mathrm{C}$ which switching with new Ringer every day then he teeth color were measured after 72 hours (M4), 1 week (M5), one month (M6). All stages of tooth color measurement system were performed by spectrophotometer according to CIE L*a*b* (Commission Internationale de I'Eclairage's) (Tavares et al., 2003). According to the ADA (American Dental Association) tooth color measurement, device located in the middle third of the labial surface of the teeth (figure 2).

Tooth bleaching $\Delta \mathrm{E}$ values are directly influenced by the index tooth color difference between the initial measurement and other measurements are shown and using the formula: $\mathrm{E}=\left[\left(\Delta \mathrm{L}^{*}\right) 2+(\Delta \mathrm{a} *) 2+\left(\Delta \mathrm{b}^{*}\right) 2\right] 1 / 2 \Delta$ $(\Delta \mathrm{a}=\mathrm{a} *$ post $-\mathrm{a} *$ baseline, $\Delta \mathrm{b}=\mathrm{b} *$ post $-\mathrm{b} *$ baseline, $\Delta \mathrm{L}=\mathrm{L} *$ post $-\mathrm{L}^{*}$ baseline) was achieved. Data were collected with 20 SPSS statistical software and ANOVA test value of $\mathrm{P}(\mathrm{P}<0.05)$ were obtained and studied under Tukey test was used pairs of groups.

\section{RESULTS AND DISCUSSION}

$\Delta \mathrm{E}$ averages and standard deviations for all groups and in all stages after bleaching compared to after being in tea shown in Table 1. 


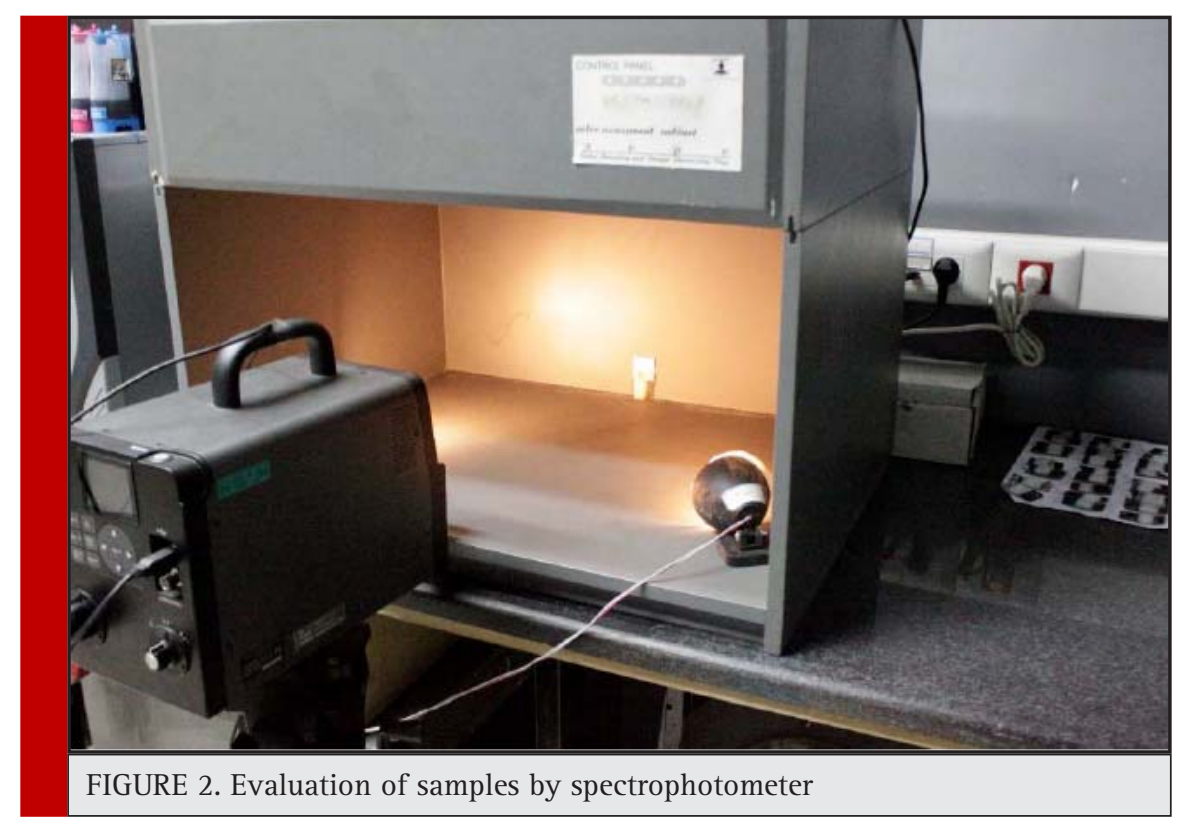

\begin{tabular}{|c|c|c|c|c|}
\hline $\begin{array}{l}1 \text { month after } \\
\text { bleaching }\end{array}$ & $\begin{array}{l}\text { 7days after } \\
\text { bleaching }\end{array}$ & $\begin{array}{l}3 \text { days after } \\
\text { bleaching }\end{array}$ & $\begin{array}{l}\text { Immediately after } \\
\text { bleaching }\end{array}$ & Groups \\
\hline $6 / 74(1 / 12)$ & $3 / 92(0 / 82)$ & $4 / 95(0 / 9)$ & $3 / 8(0 / 57)$ & Polaoffice+without light \\
\hline $9 / 83(2 / 78)$ & $3(0 / 8)$ & $3 / 82(0 / 77)$ & $2 / 89(1)$ & Opalescence Boost without light \\
\hline $7 / 25(0 / 88)$ & $4 / 78(0 / 49)$ & $5 / 39(0 / 58)$ & $3 / 57(0 / 56)$ & LED Polaoffice+ \\
\hline $7 / 17(1 / 08)$ & $98 / 3(0 / 53)$ & $4 / 21(0 / 37)$ & $3 / 28(0 / 54)$ & LED Opalescence Boost \\
\hline $6 / 58(1)$ & 10/84 (1/11) & 10/3 (1/09) & $8 / 82(1 / 21)$ & QTH Polaoffice+ \\
\hline $6 / 32(0 / 81)$ & $8 / 44(0 / 45)$ & $8 / 08(0 / 45)$ & $7 / 28(0 / 4)$ & QTH+Opalecensce Boost \\
\hline
\end{tabular}

Significant difference between $\Delta \mathrm{E}$ of groups (at times immediately, three days and one week after white) oneway ANOVA test was observed ( P-Value $<=0.05$ ). $\Delta \mathrm{E}$ significant difference between the groups was observed one after month the bleaching. $(\mathrm{P}=0.57)$

Comparing of pairs of groups by test Tukey, both of bleaching, a significant difference in the effectiveness of bleaching $(\Delta \mathrm{E})$ with the use of light QTH compared to LED and without the use of light (in the time immediately after bleaching, three days and 7 days after bleaching) showed that although a month later bleaching of teeth whitening showedsignificant difference in efficacy between any of these groups (Table 2).

To achieve lightening of teeth in a short time, bleaching technique in the office, using a high concentration hydrogen peroxide gel, with and without the use of light is recommended (Luk et al., 2004), (Roberto et al., 2011). Some studies have emphasized that light can be used to catalyze the hydrogen peroxide, thus accelerates the bleaching process (Dostalova et al., 2004), (Tavares et al., 2003). This issue is still discussed in articles and reviews.
In the present study, the teeth $\Delta \mathrm{E}$ after tea, significantly increased $(\Delta \mathrm{E}$ in all groups was higher than 3.3 means the discoloration caused by tea in all groups were detectable by eye) $\Delta \mathrm{E}$, difference before and after exposure to tea among all groups was not significant.

In this study, $\Delta \mathrm{E}$ changes in groups (immediately, three days and one week after bleaching), was significant,so the applicationof Polaoffice with QTH showed whitening effect. In the present study, the Tukey test results showed that in both bleaching agent (Opalescence and Pola office), QTH Light application significantly increased the effectiveness of bleaching component compared to LED or without light, immediately after bleaching teeth, 3 days and 7 days after bleaching, Because QTH heat transfer capability to the teeth is more than LED. QTH produce more heat than light on the tooth surface which can form groups that cause more tooth dehydration (Liang et al., 2012). Also, previous studies which have examined different types of light reported that QTH effect was remarkably higher in immediately after bleaching (Sulieman et al., 2005, Polydorou et al., 2013 Liang et al., 2012). 


\begin{tabular}{|l|l|l|l|l|}
\hline \multicolumn{4}{|l}{ Table 2. } \\
$\begin{array}{l}\text { P-value } \\
\text { After one } \\
\text { month }\end{array}$ & $\begin{array}{l}\text { P-value } \\
\text { After 7days }\end{array}$ & $\begin{array}{l}\text { P-value } \\
\text { After3 days }\end{array}$ & $\begin{array}{l}\text { P-value } \\
\text { Immediately }\end{array}$ & Groups \\
\hline 0.31 & 0.44 & 0.35 & 0.45 & Polaoffice with Opalescence Boost Without light \\
\hline 0.95 & 0.28 & 0.1 & 0.71 & Polaoffice with Opalescence Boost LED \\
\hline 0.84 & 0.08 & 0.08 & 0.24 & Polaoffice with Opalescence Boost QTH \\
\hline 0.93 & 0.75 & 0.93 & 0.98 & Without light Polaoffice + LED Polaoffice+ \\
\hline 0.99 & ${ }^{*} 0.00$ & ${ }^{*} 0.001$ & ${ }^{*} 0.001$ & Without light Polaoffice + QTH + Polaoffice \\
\hline 0.89 & ${ }^{*} 0.00$ & ${ }^{*} 0.002$ & ${ }^{*} 0.00$ & Polaoffice + LED with QTH + Polaoffice + \\
\hline 0.55 & 0.5 & 0.87 & 0.92 & Without light + Opalescence Boost LED + Opalescence Boost \\
\hline 0.36 & ${ }^{*} 0.00$ & ${ }^{*} 0.00$ & ${ }^{*} 0.001$ & Whithout light + Opalescence Boost QTH + Opalescence Boost \\
\hline 0.94 & ${ }^{*} 0.00$ & ${ }^{*} 0.00$ & ${ }^{*} 0.001$ & LED + Opalescence Boost QTH + Opalescence Boost \\
\hline$\Delta$ E Changes in groups at different times after bleach in arein Charts 1, 2 and 3.
\end{tabular}

In this study, $\Delta \mathrm{E}$ difference was not statistically significant a month after bleaching,in all groups, $\Delta \mathrm{E}$ was more than 3.3 which teeth bleaching was still detectable after a month with eye. Tukey test results compare pairs of groups after one month however no significant difference was observed between $\Delta \mathrm{E}$. This means that after a month no statistically significant differences between the different methods of bleaching as observed similar results from studies have concluded the same, (Polydorou et al., 2013) and (Alomari \&t El Daraa, 2010).

In this study, all groups showed obvious effect immediately after bleaching, though there is noconsiderably differences between one and three months. Although some studies have reported the effects of light on tooth whitening (Luk et al., 2004), (Domínguez et al., 2011), (Ontiveros \&t Paravina, 2009), (Wetter, Barroso, \& Pelino, 2004), but many studies have focused Light extremely ineffectiveness on teeth whitening (Lima et al., 2009), (Polydorou et al., 2013), (Roberto et al., 2011),(Bernardon et al., 2010), (Marson, Sensi, Vieira, \&t Araújo, 2008), (Mondelli, Francisconi, Almeida, \&t Ishikiriama, 2012), (Hein et al., 2003), (Papathanasiou, Kastali, Perry, \&t Kugel, 2002).

Although, in this study QTH had greater effectiveness after 7 days, but after one month treatment relapse was observed. In Polydorous study, the use of QTH for each tooth was 4times in 8 minutes (Polydorou et al., 2013), while in Liangs study, two sessions with7 days interval 3 times of 10 minute were applied (Liang et al., 2012). So in both of these study groups, teeth were exposed longer to QTH light. Relapse in treatmentin the Polydorous study only occurred in a month after treatment QTH group (Polydorou et al., 2013), which is similar to the results of our study, while both groups in the Liangs study showed relapse after a week with or without light cure system (Liang et al., 2012).

For other groupsin the Polydorous study, relapse occurred after 3 months (Polydorou et al., 2013), while in Liangs it happened sooner (Liang et al., 2012). These results can be explained by a lower concentration of bleaching agent used in study (32\% Beyond II Advanced Formula Whitening Gel) compared with current study (37.5\% Polaoffice and 40\% Opalescence Boost) and Polydorou study (38\% Opalescence Boost), although this difference is negligible. Tooth dehydration can cause brighter teeth immediately after bleaching so this can be increased by the heat transferred to the teeth (Luk et al., 2004). Tooth color becomes lighter during dehydration however returning to normal mode after rehydration. During in-office bleaching, many factors could cause dehydration teeth, including teeth isolation, heat from the light (Liang et al., 2012).

According to the results of this study at any time after the teeth bleaching, a significant difference in the effectiveness of the bleaching was observed regardless of light cure application, Which could be due to the concentration of these two bleaching gel (37.5\% Pola office + and 40\% Opalescence Boost). Also, according to the manufacturer's instructions, each of bleaching gel which hadless concentrations, longer exposure in the tooth surface (37.5\% Polaoffice 3 times for 8 minutes and 38\% Opalescence Boost only 20 minutes)so the effectiveness of bleaching materials weresimilar. Scientific community believe that light cure bleaching effectiveness occurs due to reversible dehydration (Polydorou et al., 2013) so in long-term we should expect relapse of treatment. The results obtained in this study during a month is not only confirmed the stability of tooth 
color But also enhances the white color of the teeth in both LED and without light cure system. The Greenwall hypothesis is that during bleaching, teeth get aerated by oxygen and oxidation processes caused by dehydration change the visual characteristics of the teeth. This partly is explained why teeth become whiter in this study after a month. For this reason, after a two-week period, scattered oxygen rehydrate and teeth show their true colors (Greenwall, 2001).

While in current study, the majority of teeth bleached within a month except QTH group which heat lead to improve the effectiveness of treatment in few first days, another parameter that can affect the outcome of the study is the viscosity of bleaching gel. Opalescence Boost was replaced with Opalescence Xtra Boost some time ago, although, manufacturer claim no chemical change, but the foundation and consistency has changed; the new bleaching gel is more viscous than before. The composition and sticky bleaching gel affect on the release of hydrogen peroxide which impact on bleaching process (Christian Hannig, Weinhold, Becker, Et Attin, 2011), (Hannig, Zech, Henze, Dreier, \&t Attin, 2005), (Thitinanthapan, Satamanont, \&t Vongsavan, 1999). high viscosity bleaching agents compared to low one shows higher peroxide emissions (Christian Hannig et al., 2011).

This change in viscosity after bleaching can cause different behavior because the viscosity of the material affects the free movement of peroxide (peroxide release kinetics). The clinical perspective, highlights light cure effect on the confidence and satisfaction of patients to continue bleaching. After a month there was no significant difference between the three groups and this shows that bleaching by light relapse sooner and do not maintain long-term effect.

\section{CONCLUSION}

According to data obtained from this study, the following results can be obtained. In office- bleaching, with and without light, is effective to bleach teeth. In both type of bleaching, bleaching effectiveness of QTH increases significantly compared to LED and without the use of light, at times of instantly, 3 days and 7 days after bleaching.Light cure does not lead to increase effectiveness of bleachingwithin a month.

\section{REFERENCES}

Alomari Q, El Daraa E. 2010 A randomized clinical trial of inoffice dental bleaching with or without light activation. Contemp Dent Pract. 11:17-24.

Barghi N. 1998 Making a clinical decision for vital tooth bleaching:At-home or in-office? Compendium Continuing Educationin Dentistry 19(8): 831-838.
BernardonK,Sartori N, Ballarin A, Perdigão, Lopes GC, Baratieri LN. 2010 Clinical performance of vital bleaching techniques. Oper Dent. 35:3-10.

Buchalla W, Attin T.2007 External bleaching therapy with activation by heat, light or laser: a systematic review. Dent Mat 23: 586- 96.

Domínguez A, García A, CostelaA,Gómez C. 2011 Influence of thelight source and bleaching gel on the efficacy of the tooth whiteningprocess. Photomed Laser Surg 2011; 29: 53-9.

Dostalova T, Jelinkova H, Housova D, Sulc J, Nemec M, Miyagi M 2004 Diode laser activated bleaching. Braz Dent J 15:3-8.

Greenwall L. 2001 Bleaching Techniques in Restorative Dentistry. London: Martin Duntz Ltd

Hahn P, Schondelmaier N, Wolkewitz M, Altenburger M, Polydorou 0. 2013 Efficacy of tooth bleaching with and without light activation and its effect on the pulp temperature. Odontology. 2013 Jan;101(1):67-74.

Hannig C, Weinhold HC, Becker K, Attin T. 2011 Diffusion of peroxides through dentine in vitro with andwithout prior use of a desensitizing varnish. Clin Oral Investig 15(6) :863868.

Hannig C, Zech R, Henze E, Dreier S, Attin T.2005 Peroxide release into saliva from five different homebleaching systems in vivo. Am J Dent. 18(1): 13-18.

Hein DK, Ploeger B, Hartup K, Wagstaff RS, Palmer TM, Hansen LD.2003 In-office vital tooth bleaching - what do lights add? CompendContinEduc Dent. 24:340-52.

Ishikaw-Nagai S,TeruiT,Ishibashi K, et.al. 2004 Prediction of optical efficacy of vital tooth bleaching using regression analysis. Color Research and Application 29:390-4

Joiner A. 2004 Tooth colour: a review of the literature. Dentistry 32:3-12.

Kohn WG, Harte A, Malvitz DM, Collins AS, Cleveland L, Eklund K; Centers for Disease Control and Prevention. CDC.2004 Guidelines for Infection Control in Dental HealthCare Settings-2003. Am Dent Assoc. 2004 Jan;135(1): 33-47.

Kossatz S, Dalanhol AP, Cunha T, Loguercio A, Reis A.2011 Effect oflight activation on tooth sensitivity after in-office bleaching. OperDent 2011; 36: 251-7.

Kumar M, Sequeira PS, Peter S, Bhat GK. Sterilisation of Extracted Human Teeth for Educational Use. Indian J Med Microbiol 2005;23(4):256-258.

Kurachi C, Tuboy AM, Magalhães DV, Bagnato VS. 2001 Hardness evaluation of a dental composite polymerizedwith experimental LED-based devices. Dent Mater 2001; 17: 309-15.

Liang S., Y Sa, L Sun,X Ma, Z Wang, W Xing 2012 Effect of halogen light irradiation on hydrogen peroxide bleaching: an in vitro study. Australian Dental Journal. 57: 277-283.

Lima DA, Aguiar FH, Liporoni PC, Munin E, Ambrosano GM,Lovadino R. 2009 In vitro evaluation of the effectiveness of bleachingagents activated by different light sources. Prosthodont 2009; 18: 249-54. 
Luk K, Tam L, Hubert M. 2004 Effect of light energy on peroxide tooth bleaching. Am Dent Assoc. 135:194-201.

Marson FC, Sensi LG, Vieira LC, Arauo E. 2008 Clinical evaluation of in-office dental bleaching treatments with and without the use of light-activation sources. Oper Dent. Jan-Feb; 33(1):15-22.

Mondelli RF, Azevedo F, Francisconi AC, Almeida CM,Ishikiriama SK. 2012 Comparative clinical study of the effectiveness ofdifferent dental bleaching methods - two year follow-up. ApplOral Sci. 20(4):435-43.

Nikita V Lolayekar, Vidya Bhat S, Sham S Bhat. 2007 Distinfection Methods of Extracted Human Teeth. Oral Health Comm Dent 2007;1(2):27-29.

Ontiveros C, ParavinaRD.2009 Color change of vital teeth exposed to bleaching perfomed with and without supplementary light. Dent. 37:450-7.

Papathanasiou A, Kastali S, Perry RD, Kugel G.2002 Clinical evaluation of a 35\% hydrogen peroxide in-office whitening system.CompendContinEduc Dent. 23:335-8.

Polydorou 0, Wirsching M, Wokewitz M, Hahn P. 2013 Threemonthevaluation of vital tooth bleaching using light units: a randomizedclinical study. Oper Dent. $2013 \mathrm{Jan}-\mathrm{Feb}$; 38(1): 21-32.

Roberto AR, Jasse FF, Boaventura JMC, Martinez TC, Rastelli ANS, Junior OB 2011 Evaluation of tooth color after bleaching with and without light-activation. Rev OdontoCienc. 26(3):247-252.
Sulieman M, Addy A, Rees JS. 2003 Development and evaluation ofa method in vitro to study the effectiveness of toothbleaching. J Dent. 31:415-22.

Sulieman M, Addy M, MacDonald E, Rees S. 2004 The effect of hydrogen peroxide concentration on the outcome of tooth whitening: an in vitro study. Dentistry 32: 295-9.

Sulieman M, MacDonald E, Rees S, Addy M.2005 Comparison of three in-office bleaching systems based on 35\% hydrogen peroxide with different light activators. Am Dent.18:194-7.

Tavares M, Stultz J, Newman M, Smith V, Kent R, Carpino E 2003 Light augments tooth whitening with peroxide. J Am Dent Assoc 134:167-75.

Tay LY, Kose C, Loguercio AD , Reis A. 2009 Assessingthe effect of a desensitizing agent used before in-officetooth bleaching ournal of the American Dental Association 140(10):1245-1251.

Thitinanthapan W, Satamanont P, Vongsavan N 1999 In vitro penetration of the pulp chamber by three brandsof carbamide peroxide. J Esthet Dent. 11(5):259-264

Wetter NU, Barroso MC, Pelino EP. 2004 Dental bleaching efficacy with diode laser and LED irradiation: an in vitro study. Lasers Surg Med. 35:254-8.

Yap AU, Soh MS.2003 Thermal emission by different light curingunits. Oper Dent 2003; 28: 260-6.

Zhang C, Wang X, Kinoshita 2007 Effects of KTP laser irradiation, diode laser and LED on tooth bleaching: a comparative study.Photomed Laser Surg 2007; 25: 91-5. 